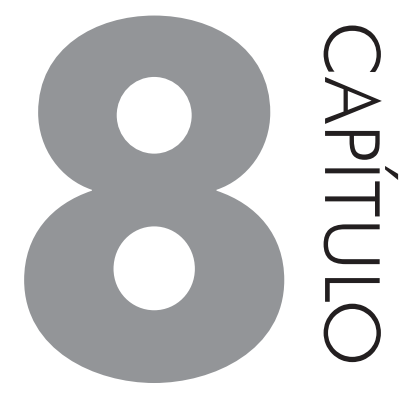

\title{
EXPERIÊNCIAS IMERSIVAS E REALIDADE VIRTUAL NA EDUCAÇÃO: ABORDAGENS INICIAIS
}

\section{INTRODUÇÃO}

\section{OFELIA ELISA TORRES MORALES}

O presente texto apresenta contribuições iniciais focalizadas na relação da educação e da comunicação. Por um lado, as primeiras reflexões destacam as relações entre educação, novas tecnologias e ciência, no uso, consumo e apropriação de conteúdos educacionais interativos com o objetivo de aliar a comunicação e a educação na formação da perspectiva da cidadania, da ciência, tecnologia e inovação. O processo de ensino e aprendizagem, em tempos de convergências midiáticas, deve estar cada vez mais próximo dos alunos e professores, a partir de suas vivências, deveres e direitos como cidadãos. É conveniente que a escola caminhe junto dos jovens estudantes indo ao encontro do seu cotidiano. Dessa forma, oportunizando processo de ensino-aprendizagem que propicie a curiosidade investigativa pelo conhecimento, aproximando-se de suas práticas vivenciais, as quais estão imersas nessa ambiência da convergência e de relacionamentos em rede.

A escola deve ser um centro de formação humana, cidadã e profissional, além de um espaço privilegiado de socialização dos jovens, de desenvolvimento de suas aptidões e sonhos. Por isto mesmo, a estrutura educacional precisa ser repensada, buscando aproximar-se da realidade dos jovens e da cultura juvenil, proporcionando sempre o acesso e a inclusão de todos os jovens (...). (SNJ, 2011, p. 8) 
É necessário que a escola se adapte aos novos contextos em que os alunos experimentam a vida, sendo cada vez mais próximos das novas tecnologias, de permanente construção de identidades, em tempos de mobilidade. Toma-se como prerrogativa que, para entender a construção das identidades dos sujeitos nos "tempos líquidos" (Bauman, 2007), deve se reconhecer que a ambiência contemporânea está marcada pela cultura da convergência, motivo pelo qual existem fragmentação e pluralidade na identidade dos sujeitos. As práticas escolares devem ser percebidas nesse paradigma da pós-modernidade e da cultura da convergência, termo definido por Jenkins $(2009$, p. 29) quem considera a convergência como aliada às transformações, sejam elas tecnológicas, mercadológicas, culturais e sociais. Entretanto, o autor destaca que ela representa uma transformação cultural, isto é, "a convergência não ocorre por meio de aparelhos, por mais sofisticados que venham ser. A convergência ocorre dentro dos cérebros de consumidores individuais e em suas interações sociais com outros". (Jenkins, 2009, p. 30)

Por outro lado, existem variados exemplos relacionados à realidade virtual vinculados ao desenvolvimento da ciência, mais especificamente, às disciplinas de ciências nas escolas e nas universidades. Nesse sentido, segue-se a linha de pensamento de Vogt (2003, p. 1) quando se refere à cultura científica como:

(...) o processo que envolve o desenvolvimento científico é um processo cultural, quer seja ele considerado do ponto de vista de sua produção, de sua difusão entre pares ou na dinâmica social do ensino e da educação, ou ainda do ponto de vista de sua divulgação na sociedade, como um todo, para o estabelecimento das relações críticas necessárias entre o cidadão e os valores culturais, de seu tempo e de sua história. (Vogt, 2003, p. 1)

Da mesma forma, a ambiência significativa da ciência e tecnologia está imersa numa sociedade contemporânea caracterizada pela cultura da convergência (Jenkins, 2009), sendo que isso marca traços diferenciados para compreender a realidade. Nesse sentido, Vogt (2003) destaca ainda a "espiral da cultura científica":

Tomando-se como ponto de partida a dinâmica da produção e da circulação do conhecimento científico entre pares, isto é, da difusão científica, a espiral desenha, em sua evolução, um segundo quadrante, o do ensino da ciência e da formação de cientistas; caminha, então, para o terceiro quadrante e configura o conjunto de ações e predicados do ensino para a ciência e volta, no quarto quadrante, completando o ciclo, ao eixo de partida, para identificar aí as atividades próprias da divulgação científica. (Vogt, 2003, p. 3) 
Fica claro, na Figura 1, como o processo se completa. Contudo, considerando-se que os tempos são de convergência, cada vez mais, as lógicas de uso, produção, consumo e apropriação da cultura científica e da inovação tecnológica também mudaram, adaptando-se às transformações advindas pela sociedade do conhecimento, da mobilidade e das redes sociais digitais.

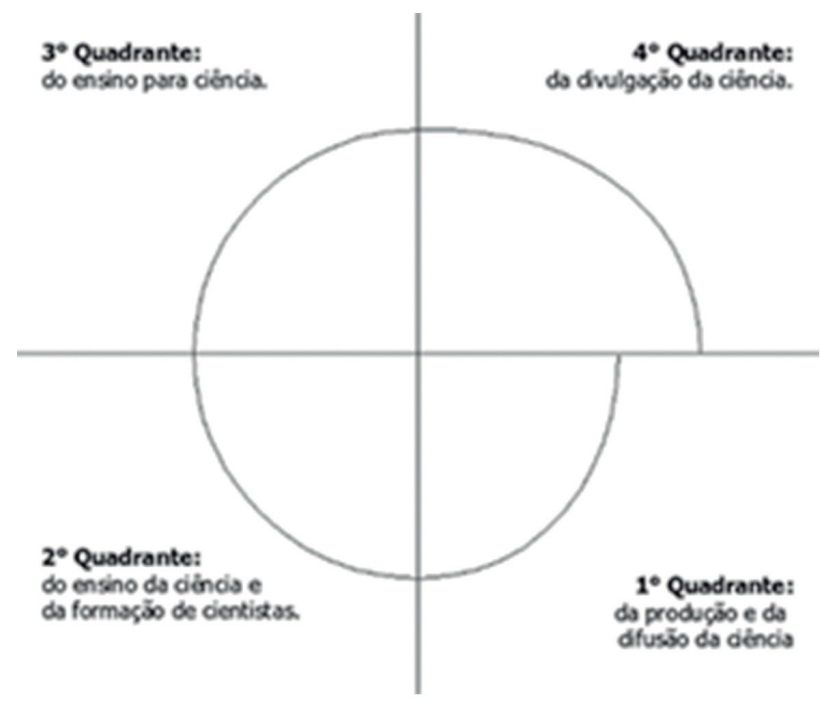

Figura 1 Espiral da cultura científica.

Fonte: Vogt (2003, p. 3).

O contexto tecnológico atual como mediação revela sua inserção no paradigma pós-moderno, o qual pulveriza o sujeito, em várias individualidades, porém, criando as suas subjetividades em redes de sociabilidade, oportunizadas pela relação tempo-espaço líquidos (Bauman, 2007). A rotina contemporânea fortaleceu aspectos da mobilidade constante, repercutindo, assim, na configuração das identidades dos jovens estudantes. Trata-se, portanto, de uma cultura "líquida", entendida, nesse texto a partir dos jovens estudantes e professores, em contextos de sociabilidade em rede, tomando como prerrogativa os estudos de Castells (2008, p. 448) quando afirma que os dispositivos móveis disponibilizam a configuração de uma identidade plural: "somos nós e nossas redes", ao mesmo tempo.

As novas mídias contribuem na relação ensino-aprendizagem a partir do intercâmbio de informações e conceitos, num ambiente que é mediatizado pela questão técnica, porém, viabiliza o encontro pedagógico de forma natural, além da sala de aula, possibilitando relacionamento próximo entre os protagonistas do processo educativo. Dessa forma, oferece possibilidades de pensar coletivamente, na construção do discurso e do conhecimento colaborativos. 
Morán (2013) relembra que:

Com as tecnologias atuais, a escola pode transformar-se em um conjunto de espaços ricos de aprendizagens significativas, presenciais e digitais, que motivem os alunos a aprender ativamente, a pesquisar o tempo todo, a serem proativos, a saber tomar iniciativas e interagir. (Morán, 2013, p. 30)

Segue-se a concepção de Zygmunt Bauman (2007), no sentido de que a vida contemporânea é "líquida", ou seja, a sociedade está marcada pela cultura da convergência sendo cada vez mais necessário, portanto, aproximar-se as novas mídias oportunizadas pela Internet, nas plataformas móveis, já que essas mídias poderiam contribuir na popularização da ciência, da tecnologia e da inovação, na perspectiva da cultura da mobilidade. Por isso, é conveniente aproximar-se a esse novo universo cognitivo disponibilizado pelas redes sociais digitais e dispositivos móveis no ensino das ciências. Como salienta Caldas (2011, p. 11), é necessário o aperfeiçoamento no ensino de ciências nas escolas, já que é "considerado essencial para a formação de uma cultura científica".

A utilização das novas mídias como ferramentas educomunicativas é crescente. Recomenda-se, portanto, a alfabetização digital no sentido de auxiliar na construção do conhecimento e identidade do aluno.

Conforme Morán (2013), não são os recursos que definem a aprendizagem, são as pessoas, o projeto pedagógico, as interações, a gestão. Mas não há dúvida de que o mundo digital afeta todos os setores", inclusive as formas "de comunicar-se e de aprender. (Morán, 2013, p. 12)

Em relação ao espaço escolar, o professor como eixo mediador do processo de ensino aprendizagem potencializaria a sua ação didática no sentido de motivar aos alunos no desenvolvimento de novos conhecimentos. Assim, fomentando a visão crítica dos conteúdos veiculados na internet devido ao amplo leque de informações disponibilizado nas plataformas hipermidiáticas. Além disso, o uso significativo dos edublogs, entre outros, como ferramentas educativas, por exemplo, também destacaria o protagonismo dos jovens, com espaços de expressão, dúvidas, compartilhamento de experiências e afirmação individual e criação de sua subjetividade.

\section{AS DIVERSAS FACES DA REALIDADE VIRTUAL, AS IMAGENS LIQQUIDAS E AS NARRATIVAS IMERSIVAS}

O presente texto nutre-se das primeiras abordagens em relação às mutações que os retratos imagéticos apresentam em tempos de convergências. Tomando-se como prerrogativas os paradigmas já apontados por Bauman (2007) e Jenkins (2009) relacionados aos tempos líquidos e a cultura da convergência, as possibi- 
lidades são múltiplas e têm impactado, também, na área das imagens em movimento as quais são consideradas aqui como imagens líquidas. A partir do sentido da inovação tecnológica, os novos formatos audiovisuais expressados pela realidade virtual (VR), por exemplo, permitem apontar o desenvolvimento das narrativas imersivas de forma diferenciada.

A realidade virtual (VR) é uma experiência que ultrapassa o visual já que ela oportuniza o sentido de imersão, na relação da percepção do real-imaginário. Mostrando a ambiência de forma ampla, oferece a sensação de interação do sujeito-participador com essa realidade virtual criando a percepção de interagir com o que está sendo mostrado. Isto oportunizado pelas produções audiovisuais de realidade virtual (VR) com captação em câmeras de 360 graus, uso de Smartphones e com a recepção em óculos de realidade virtual, entre os mais conhecidos o Oculus Rift, o Gear VR ou a iniciativa da Google em popularizar a recepção da realidade virtual com o Cardboard.
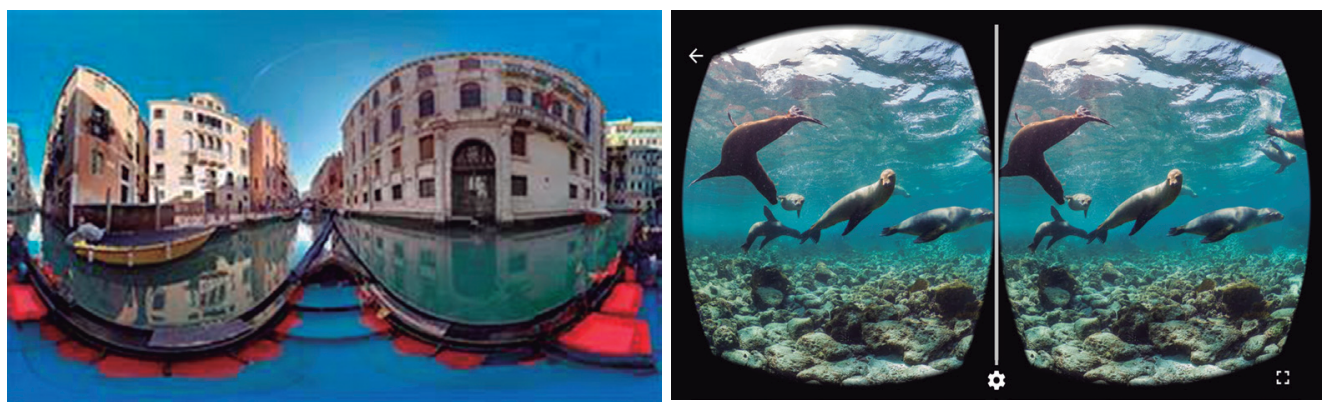

Figura 2 Imagens de vídeo em 360 VR.?

O conceito “imersão" inicialmente foi reconhecido como expressão da relação entre os games e os jogadores, como sensibilização e integração que os participadores (gamers) sentem "como se fossem" partes integrantes do contexto sugerido pela realidade recriada por esses jogos virtuais. Assim, as narrativas imersivas surgem com essa marca de interatividade, de ser coparticipantes da história contada já que o sujeito-participador tem a impressão vivencial dessa experiência. Essa interface entre tecnologia e criatividade oportuniza aos realizadores variadas e sofisticadas formas de apreender o mundo a partir do audiovisual. Idealizar e realizar histórias com imagens em movimento torna-se cada vez mais complexo, em termos de estórias, mas ao mesmo tempo, revelam recortes imagéticos inovadores, numa fusão de arte e tecnologia.

1 Aventuras no conhecimento. Disponível em: <http://www.aventurasnoconhecimento.com. br/2017/02/vr-360-os-melhores-aplicativos-games-e.html>. Acesso em: 27 out. 2017. 
Segundo Santaella (2010), “a ideia de imersão, usando estereoscopia, medição da direção dos olhos e outras tecnologias para criar a ilusão de estar dentro de uma cena gerada pelo computador é uma das fundações da Realidade Virtual" (p. 192-3). Atualmente, as formas em que a VR se apresenta são variadas e tecnologicamente cada vez mais sofisticadas propiciando alta conectividade, chegando ao que se identifica como Realidade Aumentada (AR), inclusive, a qual combina dados virtuais - como hologramas, por exemplo - às visualizações do mundo real, ou seja, o sujeito-participador continua vendo o mundo real, contudo, complementado de alguns elementos virtuais. Porém, no presente texto, referimo-nos à realidade virtual oportunizada pelo uso de câmeras $360 \mathrm{VR}$, as quais oferecem representações imagéticas que se aproximam ao real concreto, com verossimilhança, o qual cria as condições favoráveis para "Olhar e sentir-se parte de" uma outra realidade. Conforme Santaella (2010) afirma, a realidade virtual "quebra a barreira da tela, abrindo o espaço multidimensional à habitação cognitiva e sensória do usuário" (p. 194), isto é, observamos o rio e, ao mesmo tempo, podemos nadar nele.

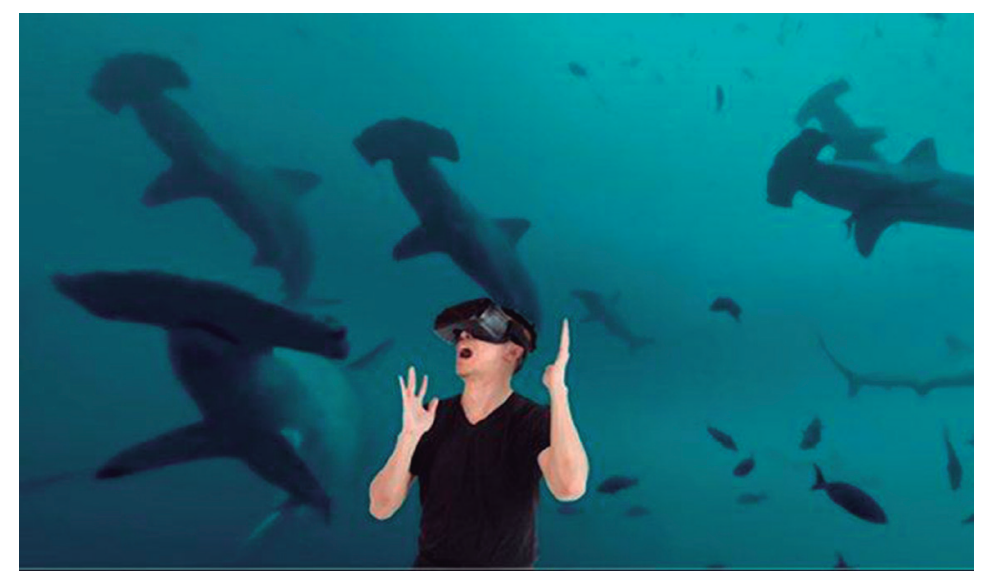

Figura 3 Experiência imersiva com uso de Oculus Rift. ${ }^{2}$

A realidade virtual envolve três conceitos, segundo Zanchet e Montero (2003),

1) Imersão mental: que acontece quando se olha uma imagem tridimensional em uma tela e imersão física: que requer o uso de periféricos sofisticados como capacetes estereoscópicos e datagloves, que dão a impressão de se ter passado através do espelho da tela. 2) Navegação que é a capacidade de se

2 DISCOVERY PROMOTES SHARK WEEK WITH VR AD ON HOMEPAGE (2017). Disponível em: <https://www.mediapost.com/publications/article/305180/discovery-promotes-shark-week-with-vr-ad-on-homepa.html>. Acesso em: 27 out. 2017. 
mover e de se encontrar no universo virtual. 3) Interação que é a possibilidade de interagir com a imagem e manipulá-la como se fosse matéria. (Zanchet \& Montero, 2003, p. 489)

Ainda em relação ao conceito de imersão, a autora Janet Murray (2003) nos indica alguns caminhos: "A imersão pode requerer um simples inundar da mente com sensações (...). Muitas pessoas ouvem música desta maneira, como um aprazível afogamento das partes verbais do cérebro" (Murray, 2003, p. 102). É como se se entrasse em uma sintonia diferenciada que transportasse ao sujeito-participador a outro mundo, de natureza virtual, fora do seu mundo real, criando um acordo pessoal no qual mergulha para validar essa outra dimensão. Assim, torna-se a vivência do virtual como se fosse real, ou seja, acreditando na sensação de participar de outra história, porém, na dimensão da virtualidade completando, de forma criativa, essa experiência virtual: "Por causa de nosso desejo de vivenciar a imersão, concentramos nossa atenção no mundo que nos envolve e usamos nossa inteligência mais para reforçar do que para questionar a veracidade da experiência”. (Murray, 2003, p. 111).

Seguindo essa linha de pensamento, conforme Dautun (apud Catalã, 2011, p. 34),

É necessário buscar o caminho pelo qual a imagem nos é imposta, os meios pelos quais atua em nós. Já que somos nós que a fazemos falar - o que nos diz não provém dela, mas de nós mesmos -, o que vem dela é aquilo que nos leva a dizer. Portanto, o que é preciso buscar é o conjunto de meios que nos levaram a perceber algo, e então tirar conclusões dessa percepção. É necessário descobrir como a imagem conduz, determina (organiza e até, de fato, manipula) nossa percepção, dirige nosso olhar e com ele as ideias que surgiram desse olhar orientado dessa maneira. Trata-se de aprender a olhar como funciona nosso olhar. (Dautun, apud Catalã, 2011, p. 34)

Isto é, a percepção do nosso olhar, na ambiência da realidade virtual, amplia-se oferecendo múltiplas opções do sentido de ver e de sentir. A imersão disponibiliza ao sujeito-participador a sensação de escolhas de uma trajetória própria e única que ele opta quando entra nessa realidade virtual oportunizada nas narrativas imersivas das produções de 360 graus. Ou seja, o fato de que o sujeito-participador se sinta realmente partícipe da estória oportuniza uma narrativa imersiva, proposta pelo realizador, contudo, vivificada e completa pelas opções realizadas pelo participador. Essa narrativa imersiva também é favorecida pela sofisticação tecnológica que tem gerado plataformas móveis, com possibilidade de transformar seu Smartphone em um dispositivo de realidade virtual, combinando-se com os Oculus específicos. Sendo assim, essa experiência imersiva pode ocorrer em qualquer tempo e espaço. Por isso, metaforicamente, essas imagens 
criadas no contexto da realidade virtual poderiam ser identificadas como imagens líquidas, seguindo as reflexões de Bauman (2007) sobre os tempos líquidos como metáfora da sociedade pós-moderna. (Bauman, 2007)

Ainda em relação à interatividade das imagens líquidas disponibilizadas pela VR, nessa interação predomina a sensação de imersão de ser partícipe, contudo, seria um nível sensorial inicial. Pela observação direta desse fenômeno pela presente pesquisadora, entende-se que existiriam níveis de imersão e de interação, os quais variariam segundo a sensação de transparência em que o sujeito-participador realmente interagiria com o mundo virtual/real. Ou seja, existiriam nuances de interação diferenciadas quando se pensa em realidade virtual (VR) e em realidade aumentada (AR), por exemplo.

Nesse sentido, o presente texto apresenta reflexões iniciais sobre o que se considera como realidade virtual (VR) pela sua repercussão nas imagens em movimento nos tempos contemporâneos. A experiência visual em realidade virtual (VR) impacta nos aspectos éticos, estéticos e técnicos da concepção audiovisual. Por um lado, a estratégia estética que disponibiliza ao sujeito-participador, sugerindo a plena interação com a experiência visual de 360 graus, isto é, a sensação dele "estar dentro" do próprio filme já que ele oferece ampla visão, é a mudança crucial na natureza do audiovisual que traz a VR: de sentir-se integrante do universo imagético mostrado. Por outro lado, esse câmbio estético traz implicações éticas, ao mesmo tempo, já que ao mostrar-se os ambientes na sua totalidade, numa espécie de amplitude cognitiva geral, gera a oportunidade de sentir-se integrante da concretude de uma macrorrealidade. Isto, aliado ao incentivo de ser partícipe da imagem e de criar a sensação de interagir, permite olhar de forma diferenciada a realidade.

Além disso, as possibilidades que proporcionam os vídeos de 360 graus geram mudanças em vários aspectos na produção, exibição e recepção do que consideramos como imagens líquidas em tempos de convergência midiática. Muitas das regras utilizadas na linguagem audiovisual (Watts, 1999), tradicionalmente, como, por exemplo, a "regra dos 180 graus", diluem-se diante da ampliação das tonalidades do espaço imagético criado, já que é uma nova dimensão oferecida pela captação ampliada em 360 graus. É, a realidade virtual mudou até as tradicionais regras audiovisuais como a regra dos 180 graus a qual fica totalmente fragmentada com a inclusão dos cardboards, os quais facilitam essa imersão audiovisual. Da mesma forma, as regras relacionadas aos enquadramentos das imagens, por exemplo, ficam mais complexas já que se trata de ampla visão, sendo que cada elemento tem uma expressividade própria, diga-se, metaforicamente como um soneto, porém, que se completa ao interagir uns elementos com os outros, resultando numa complexa sinfonia visual e multimídia. Nessa experiência 
de narrativas imersivas surgem vários elementos interatuantes, combináveis, que o sujeito-participador concretizará ao escolher uma trajetória. A utilização das regras de enquadramento será mais complexa no sentido de acompanhar as pontuações oferecidas pelas narrativas imersivas do VR. A "regra dos terços", por exemplo, talvez possa ser utilizada a partir dos personagens e das pontuações dos enredos narrativos. Ainda ficam algumas questões em relação a esse novo formato para repensarmos como essas técnicas podem ser absorvidas no VR. Por isso, trata-se de uma reconfiguração na gramática audiovisual, a partir da linguagem disponibilizada pela VR, ainda em processo de experimentação. Entende-se que vários elementos tradicionais na linguagem audiovisual serão adaptados para essa nova compreensão da visualidade em 360 graus.

Em termos de produção e realização existem variados tipos de câmeras de 360 graus e acessórios que facilitam esse acesso na realização, tomando em conta que são vários aspectos técnicos que devem ser planejados com cuidado pelo fato da visualização em 360 graus, a qual não oculta os elementos utilizados durante a gravação já que estarão todos expostos durante a gravação, tanto no vídeo como no som. Além disso, o processo de edição é mais complexo e sofisticado, tomando-se a exigência profissional. A sensação de integração e de interatividade do sujeito-participador com a ambiência das imagens em 360 graus, ou seja, de sentir-se parte da história, é uma mudança que essa experiência multimídia em tempos de convergência midiática traz como um dos principais desafios para entendermos essa inovação tecnológica que tem impactado nos processos de produção e realização dessas experiências em 360 graus.

Trata-se de contar histórias, com imagens em movimento. Porém, no campo das experiências audiovisuais em 360 graus, nas narrativas imersivas podem existir várias linhas de narração simultaneamente. Sendo assim, entende-se que as narrativas imersivas são não lineares. Então, a roteirização fica cada vez mais complexa, a partir de personagens ou situações de conflito narrativo. Uma diferença crucial é o fato de que o sujeito-participador se sente dentro da história, ele vive essa experiência como real, de forma simultânea, podendo interagir com todos os elementos ao seu entorno e, ao mesmo tempo, oportunizando-se diversos caminhos de narrativa. O realizador de VR, ao roteirizar sua proposta, teria que oferecer sinais das possibilidades de caminhos que o sujeito-participador poderá trilhar, isto não de uma forma maniqueísta, contudo, na criação de enredos e estórias que podem ser percorridos. Caberá ao participador optar por uma trilha ou outra ou na combinação dos elementos para mergulhar na estória. É uma experiência imersiva, "dentro de" e não "fora de". Dessa forma, criar o roteiro dessas experiências de 360 VR é um desafio criativo como também inovador já que ainda há muito a desbravar nesse sentido. Mas, há algo em comum com as experiências imagéticas em outros formatos, que é a importância de contar boas 
histórias. Isso é primordial, seja qual for a escolha de mídia, seja cinema, televisão, web-série, entre outras. E contar boas histórias com imagens em movimento também faz parte importante das narrativas imersivas surgidas a partir dessas experiências inovadoras em 360 graus.

Esse olhar sensível, a partir das experiências das narrativas imersivas, oportunizadas pelas produções em 360 graus, revela os recortes imagéticos ampliados, criados em tempos das convergências midiáticas. Então, pode-se dizer que a cultura da convergência trouxe também suas formas de expressão, no caso, narrativas e estórias, impregnadas de suas características, salientando os relatos do conhecimento colaborativo. Em outras palavras, desenraizar visualmente o visual, vinculado ao nosso olhar e aprofundar na relação de como ele se completa, no que consideramos o trajeto do nosso olhar, potencializado pela tecnologia utilizada.

\section{ALGUMAS EXPERIÊNCIAS DAS IMAGENS LIQQUIDAS EM REALIDADE VIRTUAL}

A educação pode apropriar-se das novas tecnologias para auxiliar no processo e ensino-aprendizagem já que os estudantes convivem nesse tempo de convergências midiáticas. São vários os recursos didáticos que disponibilizam os materiais criados em realidade virtual para o ensino de ciências na escola como também no nível universitário.

Google tem tido iniciativas expressivas relacionadas à educação, entre elas a Google Expeditions 3 , como relatam: "Excursões para qualquer lugar Machu Picchu, Antártida ou Estação Espacial Internacional: para onde você quer levar sua turma?" 4 Por exemplo, as viagens de campo virtuais, como mostra o vídeo do Youtube sobre a experiência dos alunos do $7^{\circ}$ ano de Eagle Grove, Iowa, EUA, em visita ao edifício Burj Khalifa, em Dubai ${ }^{5}$, podem ser realizadas a partir da realidade virtual oportuniza as visitas de campo virtuais, que possibilitam que os estudantes possam conhecer locais longes, como por exemplo museus e ambientes ecológicos fisicamente distantes, porém, com os dispositivos da realidade virtual, possibilita vivenciar a experiência de conhecê-los "como se fosse" presencialmente. O campo das produções de vídeo em realidade virtual

3 GOOGLE EXPEDITIONS. Disponível em: <https://edu.google.com/expeditions/\#about>. Acesso em: 21 out. 2017.

4 GOOGLE EXPEDITIONS. Disponível em: <https://edu.google.com/expeditions/\#about Acesso>. Acesso em: 21 out. 2017

5 YOUTUBE. Google Expeditions: over a million students, on trips to virtually anywhere. Disponível em: <https://edu.google.com/expeditions/\#explore>. Acesso em: 21 out. 2017. 
tem um mercado crescente de realizadores e realizações nesse sentido. Isso permite que os professores orientem essas visitas virtuais guiando e reforçando os principais pontos de destaque.

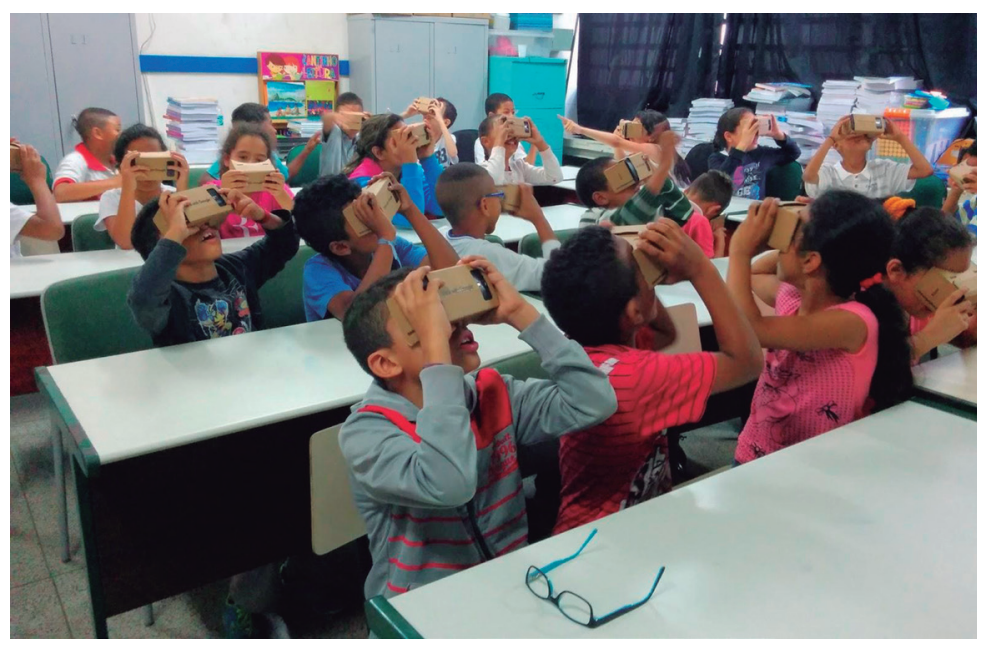

Figura 4 Alunos da Escola Estadual Santa Rosa de Lima, no Jardim Vale das Virtudes, em São Paulo, navegam no fundo do mar com o Google Expeditions, com Cardboard (2015). 6

Esse material audiovisual em realidade virtual concretiza-se com a recepção feita com o auxílio do Google Cardboard ${ }^{7}$, os quais podem ser realizados pelos mesmos alunos já que são de fácil elaboração e o curso do material é acessível. Outra opção oferecida pela Google é o Tilt Brush, aplicativo que permite as pessoas pintar no ar, o qual potencializa sua importância em diversas disciplinas do ensino médio fundamental, como educação artística e na área de história.

Ainda em relação a realidade aumentada (AR), têm sido feitas alternativas para o acompanhamento de material didático $\left[{ }^{8}\right]$ para disciplinas como ciências biológicas, mostrando o corpo humano, assim como em história, química e física, como mostra no projeto Mel Science VR ${ }^{9}$ e o seu canal no Youtube Mel Chemis-

6 GOOGLE EXPEDITIONS: a realidade virtual chega às salas de aulas no Brasil (2015). Disponível em: <https://brasil.googleblog.com/2015/11/google-expeditions-realidade-virtual.html>. Acesso em: 27 out. 2017.

7 GOOGLE EXPEDITIONS. Disponível em: <https://vr.google.com/cardboard/>. Acesso em: 21 out. 2017.

8 YOUTUBE. Education in the Future: VR and AR. Disponível em: <https://www.youtube.com/ watch? v=etn $2 \mathrm{zCa} 7 \mathrm{n} 40>$. Acesso em: 21 out. 2017.

9 MEL SCIENCE VR. Disponível em: <https://melscience.com/vr/>. Acesso em: 23 out. 2017. 
try ${ }^{10}$, na sua proposta de compreensão da química, a partir do uso elementos, procedimentos e laboratórios virtuais.

Destaca-se a experiência brasileira de realidade aumentada (AR), o Play Kids, que surgiu em 2013, startup voltada à realidade aumentada, que permite misturar aspectos do mundo real com o virtual e proporciona uma nova forma de visualizar imagens, ambiente interativo a partir do aplicativo Play Kids, já presente em mais de 100 países, da Movile, empresa-filha da Unicamp - Universidade Estadual de Campinas. Outras experiências de realidade aumentada (AR) têm auxiliado na ampliação da experiência do processo de ensino e aprendizagem. ${ }^{11}$
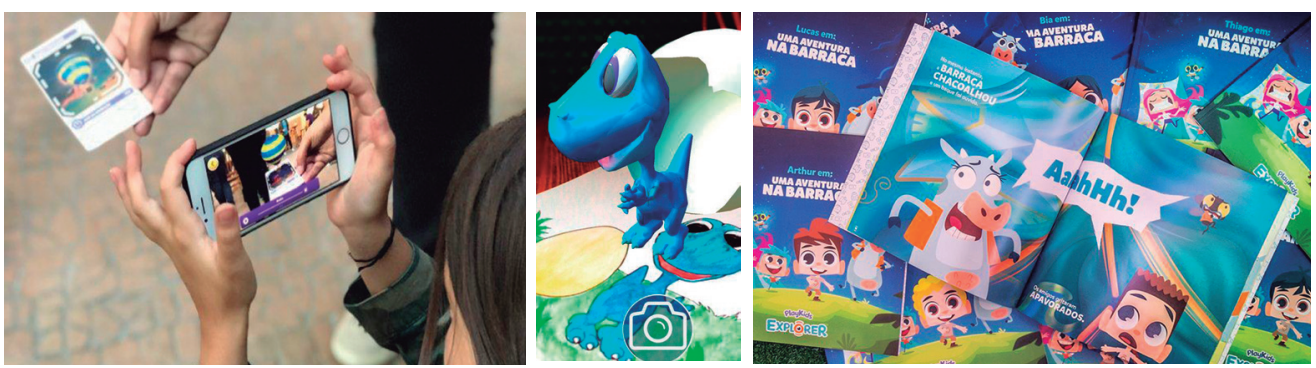

Figura 5 Realidade aumentada (AR) na experiência brasileira Play Kids.. ${ }^{12}$

O Discovery $V R^{13}$ também traz conteúdos vinculados ao gênero do entretenimento em realidade virtual, contudo, eles podem auxiliar no desenvolvimento de temáticas sobre meio ambiente, história, cultura e aventura no seu Discovery VR Atlas ${ }^{14}$. Além disso, mais uma vertente de contribuição pedagógica em VR é na área da saúde sendo que já existem alguns exemplos nos cursos universitários de medicina ${ }^{15}$, enfermagem, fisioterapia, entre outros, que também usufruem des-

10 YOUTUBE.MelChemistry.Disponívelem:<https://www.youtube.com/watch?v=pIuUZiOEo7k>. Acesso em: 23 out. 2017.

11 NESLONEY, TODD \& MINOCK, DREW. Augmented Reality Brings New Dimensions to Learning (2013). Disponível em: <https://www.edutopia.org/blog/augmented-reality-new-dimensions-learning-drew-minock>. Acesso em: 24 set. 2017.

12 MASI, Breno. Realidade Aumentada na Educação - Como a PlayKids está dando vida ao aprendizado (2017). Disponível em: <https://pt.linkedin.com/pulse/realidade-aumentada-na-educa $\%$ C3\%A7\%C3\%A3o-como-playkids-est \%C3\%A1-dando-breno-masi>. Acesso em: 27 out. 2017.

13 DISCOVERY VR. Disponível em: <http://www.discoveryvr.com/>. Acesso em: 27 out. 2017.

14 DISCOVERY VR (2016). Disponível em: <https://www.viveport.com/apps/2689d7dc-b8934a54-86a4-59c9a01d729e>. Acesso em: 27 out. 2017.

15 ZANCHET, Dinamar José \& MONTERO, Edna Frasson de Souza. Realidade virtual e a medicina. Disponível em: http://www.scielo.br/pdf/acb/v18n5/17446.pdf>. Acesso em: 8 nov. 2017. 
ses materiais em realidade virtual, não somente como aplicações em tratamentos de distúrbios neurológicos como também didaticamente como contribuição nas aulas sobre anatomia do corpo humano e até operações simuladas virtualmente pelos estudantes da saúde.

\section{CONSIDERAÇÕES FINAIS}

As mudanças no paradigma audiovisual imersivo revelam mergulho in loco na proposta de visualidade, seja no cinema, no jornalismo, na publicidade ou na educação. As imagens criadas para a VR oportunizam ao participador ou sujeito-receptor, integrar-se a imagem de forma envolvente, como se ele estivesse presente no lugar dos acontecimentos. Seja na ficção ou sejam nas reportagens e documentários, o valor agregado da natureza do VR, isto é, a sensação da imersão em que o sujeito percebe, ao interagir com essas imagens, como se fosse parte integrante desse universo, já oferece amplas possibilidades de contar histórias. No jornalismo, poderia reforçar a objetividade no sentido de mostrar a ambiência na sua totalidade, com rigor e amplitude. No cinema, as personagens e os enredos, podem cativar o sujeito-participador com sua proposta narrativa atingindo o seu emocional. Na publicidade e no campo do institucional, cada vez mais surgem novas opções de VR. Na educação, acrescenta explanações e oportuniza vivência, curiosidade investigativa e empatia pelos conteúdos em VR. As imagens em movimento têm força e criam emoção pelo seu movimento, e isso nos 360 graus VR seria mais um elemento de destaque e de presença imersiva.

As possibilidades que trazem as narrativas imersivas oportunizadas pela realidade virtual a partir das diversidades de câmeras de 360 graus VR são infinitas. As inovações tecnológicas ocorrem velozmente sendo que há muito por desbravar-se ainda na sua práxis. Contudo, o campo teórico é recente sobre essas inovações tecnológicas e suas repercussões no campo da imagética contemporânea e, nesse sentido, a presente pesquisadora pretende aprofundar essa temática em futuras pesquisas e indagações em VR.

\section{REFERÊNCIAS}

Bauman, Zygmunt. (2007). Tempos líquidos. Rio de Janeiro: Zahar.

Caldas, Graça. (2011). O valor do conhecimento e da divulgação científica para a construção da cidadania. Comunicação \& Sociedade, ano 33, n. 56, p. 7-28, jul./dez.

Castells, Manuel. (2008). Afterword. In: Katz, J. E. Handbook of mobile communication studies. Cambridge: MIT Press, 2008. p. 447-51.

Jenkins, Henry. (2009). Cultura da convergência. São Paulo: Aleph, 2009. 
Moran, José M. (2013). Ensino e aprendizagem inovadores com apoio de tecnologias. In: Moran, José, Masetto, Marcos T. \& Behrens, Marilda Aparecida. (2013). Novas tecnologias e mediação pedagógica. 21. ed. Campinas, SP: Papirus, p. 11-72.

Murray, Janet H. (2003). Hamlet no Holodeck: o futuro da narrativa no ciberespaço. São Paulo: Itaú Cultural/Unesp.

Santaella, Lúcia. (2010). Culturas e artes do pós-humano: da cultura das mídias à cibercultura. São Paulo: Paulus.

Secretaria Nacional de Juventude (SNJ). (2011). Documento Base $2^{\text {a }}$ Conferência Nacional de Juventude: conquistar direitos, desenvolver o Brasil. Brasília: Secretaria Nacional de Juventude. Disponível em: <http://www.juventude.ba.gov.br/wp-content/uploads/2011/08/>. Acesso em: 22 ago. 2014.

Vogt, Carlos. (2003). A espiral da cultura científica. Com Ciência. Disponível em: <www. comciencia.br/reportagens/cultura/cultura01.shtml>. Acesso em: 11 nov. 2016.

Watts, Harris. (1999). Direção de câmera. São Paulo: Summus, 1999.

Zanchet, Dinamar José \& Montero, Edna Frasson de Souza. (2003). Realidade virtual e a medicina. Acta Cirúrgica Brasileira, v. 18 (5), 2003. 489p. Disponível em: <http://www. scielo.br/pdf/acb/v18n5/17446.pdf>. Acesso em: 8 nov. 2017. 